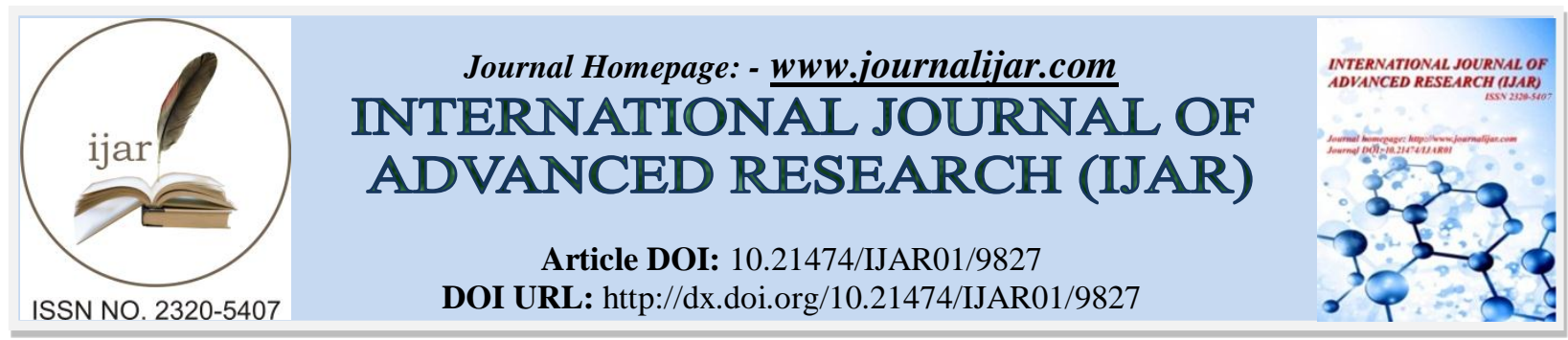

RESEARCH ARTICLE

\title{
SPECIATION AND ANTIFUNGAL SUSCEPTIBILITY PATTERN OF CANDIDA ISOLATES FROM VARIOUS CLINICAL SPECIMENS AT A TERTIARY CARE HOSPITAL, MAHARASHTRA.
}

\section{Dr. Ishan Pandita ${ }^{1}$, Dr. A. S. Wyawahare ${ }^{2}$, Dr. M.V. Mulay ${ }^{3}$, Dr. Tazammul Hussain ${ }^{4}$ and Dr. Smita} Kulkarni ${ }^{5}$.

1. PG Resident, Department of Microbiology, MGM Medical College and Hospital, Aurangabad, Maharashtra.

2. Professor, Department of Microbiology, MGM Medical College and Hospital, Aurangabad, Maharashtra.

3. Professor and Head, Department of Microbiology, MGM Medical College and Hospital, Aurangabad,

Maharashtra.

4. PG Resident, Department of Microbiology, MGM Medical College and Hospital, Aurangabad, Maharashtra.

5. Assistant Professor, Department of Microbiology, MGM Medical College and Hospital, Aurangabad,

Maharashtra.

\section{Manuscript Info}

Manuscript History

Received: 06 August 2019

Final Accepted: 08 September 2019

Published: October 2019

Key words:-

Candida species, Anti-fungal susceptibility pattern.

\section{Abstract}

Introduction: Candida species are one of the major human opportunistic pathogen. Various factors like indiscriminate use of antibiotics, AIDS and other immunosuppressive conditions have led to significant rise in Candida and other fungal infections. Emergence of Antifungal resistance has further complicated the situation.

Material and Method: This prospective study was conducted at a multispecialty tertiary care centre in Maharashtra for 18 months. A total of 164 Candida isolates from various clinical specimens were analysed. Repeat isolates from same patient were excluded. Species identification and antifungal susceptibility testing was done using Vitek 2 system.

Results: Out of 164 Candida isolates, Candida albicans 67 (40.8\%) was the most common species followed by Candida tropicalis 48 (29.3\%), Candida parapsilosis $16(\mathbf{9 . 7 \%})$, Candida famata $15(\mathbf{9 . 1 \%})$, Candida ciferrii 6 (3.6\%), Candida lusitaniae 5 (3\%). From Urine, Sputum, Pus and Bronchoalveolar lavage fluid Candida albicans was most common isolate; while non-albicans Candida species were most commonly isolated from Blood, Endotracheal secretion. Candida isolates showed maximum resistance to Voriconazole (9.7\%), followed by Flucytosine $(\mathbf{5 . 5 \%})$, Amphotericin B $(\mathbf{2 . 4 \%})$, Caspofungin $(\mathbf{2 . 4 \%})$, Micafungin $(\mathbf{2 . 4 \%})$ and Fluconazole (1.2\%).

Copy Right, IJAR, 2019,. All rights reserved.

\section{Introduction:-}

Candidiasis is an infection caused by various species of Candida. Candida species are part of normal flora of oropharynx, genitourinary tract, gastrointestinal tract and $\operatorname{skin}^{1}$, so their isolation from these systems is a complex problem as it is difficult to differentiate between commensals/pathogenic Candida species. Candida species are one of the major human opportunistic pathogen. Candida species can infect skin, oral cavity, oesophagus, nails, respiratory system, genitourinary system, blood, eyes, heart or meninges. ${ }^{1}$ In the last 3-4 decades incidence and prevalence of invasive fungal infections have significantly increased. ${ }^{2,3}$ Various factors like indiscriminate use of 
antibiotics, AIDS and other immunosuppressive conditions have led to significant rise in Candida and other fungal infections. ${ }^{4}$ In the recent years emergence of anti-fungal resistance has further complicated the situation. ${ }^{\mathbf{5}, \mathbf{6}, \mathbf{7}}$ Emergence of multi-drug resistant non-albicans Candida (NAC) as important cause of infections is also a matter of concern. ${ }^{8}$

It is well known fact that the conventional methods of identification are time consuming and Vitek -2 system is an acceptable alternative method for rapid speciation and sensitivity testing of Candida species. ${ }^{\mathbf{9}, 10,11}$ The rising burden of Candida infections and ever increasing anti-fungal resistance among Candida species necessitates accurate and rapid identification of Candida isolates for better patient outcome. ${ }^{12}$ This study was undertaken to find out institutional anti-fungal susceptibility pattern of Candida isolates for an effective anti-fungal drug therapy for Candida infection.

\section{Material and methods:-}

This study was undertaken only after approval of institutional ethical committee. It was a prospective study undertaken at MGM Medical College, Aurangabad for 18 Months ( $1^{\text {st }}$ January, 2018 to $30^{\text {th }}$ June, 2019). All clinical samples which were received in Microbiology department for routine culture and sensitivity during the study period from which Candida species were isolated were included in the study; repeat isolates from same patient from same source were excluded.

Presumptive identification of the Candida isolates was based on colony morphology on blood agar (small, 1-2 mm, creamy white, smooth, pasty, non-hemolytic colonies with yeasty odor after 24 hours incubation) ${ }^{\mathbf{1 3}}$, Gram Stain (Gram positive oval budding yeast like cells) ${ }^{\mathbf{1 3}}$ and Germ tube test (Isolate giving positive result presumptively identified as Candida albicans). ${ }^{\mathbf{1 3}}$

Final identification and antifungal susceptibility testing of Candida isolates was done using Vitek 2 compact system using Yeast card ID (VITEK 2 YST) and Yeast card AST (AST-YS07) respectively. For inoculum preparation pure sub-cultured colonies were suspended in aqueous $0.45 \%$ (wt/vol) $\mathrm{NaCl}$ to achieve a turbidity equivalent to a McFarland 1.8-2.2 McFarland standard according to the manufacturer's recommendations and measured on the DensiChek turbidity meter (Biomerieux, India). The cassettes were loaded into the Vitek-2 compact system.

Quality control was done using the following strains as controls for the evaluation: C. albicans ATCC14053 and Candida parapsilosis ATCC22019. Yeast AST card (AST-YS07) contains these 6 anti-fungal agents: Amphotericin B, Caspofungin, Flucytosine, Fluconazole, Micafungin, Voriconazole.

\section{Results:-}

A total of 164 Candida isolates were analysed. Out of 164 Candida isolates, Candida albicans with 67 (40.8\%) isolates was most common species. Among non-albicans Candida, Candida tropicalis was the most predominant species $\mathbf{( 2 9 . 3 \%}$ ) (Table $\mathbf{1})$.

\begin{tabular}{|l|l|}
\hline Candida Species & No. of isolates \\
\hline Candida albicans & $\mathbf{6 7}(\mathbf{4 0 . 8 \%})$ \\
\hline Candida tropicalis & $\mathbf{4 8 ( 2 9 . 3 \% )}$ \\
\hline Candida parapsilosis & $16(9.7 \%)$ \\
\hline Candida famata & $15(9.1 \%)$ \\
\hline Candida ciferrii & $6(3.6 \%)$ \\
\hline Candida lusitaniae & $5(3 \%)$ \\
\hline Candida glabrata krusii, & $2(1.2 \%)$ \\
\hline $\begin{array}{l}\text { Candida auris, Candida isolate }(0.6 \%) \text { each } \\
\text { Candida pelliculosa, Candida utilis } \\
\text { and Candida kefyr }\end{array}$ & \\
\hline
\end{tabular}

Table 1:-Species distribution of Candida Species

The age and sex distribution of Candida species is described in Table 2. About $51 \%$ of the Candida were isolated from adult age group (19-65) and 54\% of the isolates were from male patients. 


\begin{tabular}{|l|l|}
\hline Demographic Characteristics & Frequency \\
\hline Age Wise Distribution & $31(18.9 \%)$ \\
Paediatric age group (0-18) & $84(\mathbf{5 1 . 2} \%)$ \\
Adult age group (19-65) & $49(29.9 \%)$ \\
Geriatric age group ( Above 65) & $164(100 \%)$ \\
Total & $89(\mathbf{5 4 . 3} \%)$ \\
\hline Sex Wise Distribution & $75(45.7 \%)$ \\
Male Patients & $164(100 \%)$ \\
Female Patients & Species \\
Total Patients & \\
\hline
\end{tabular}

Table 2:-Demographic distribution of Candida Species

Candida albicans was most common isolate from Urine, Sputum, Pus, Bronchoalveolar lavage fluid etc. (Table 3). Out of 67 isolates of Candida albicans, 31 (46.2\%) isolates were from urine followed by 18 (26.8\%) isolates from sputum. Candida parapsilosis was the most common isolate from blood ( 8 isolates) while Candida tropicalis was the most common isolate from Endo-Tracheal secretions (2 isolates).

Table 3:-Specimen distribution of Candida Species

\begin{tabular}{|l|l|l|l|}
\hline Specimen & Candida albicans & Non-albicans Candida & Total Candida isolates \\
\hline Broncho-Alveolar Lavage & $2(3 \%)$ & $2(2.1 \%)$ & $4(2.4 \%)$ \\
\hline Blood culture & $4(6 \%)$ & $\mathbf{1 7}(\mathbf{1 7 . 5 \% )}$ & $21(12.8 \%)$ \\
\hline Endo-Tracheal secretions & $0(0 \%)$ & $6(6.2 \%)$ & $6(3.7 \%)$ \\
\hline Pus and Pus swab & $6(9 \%)$ & $6(6.2 \%)$ & $12(7.3 \%)$ \\
\hline Sputum & $\mathbf{1 8}(\mathbf{2 6 . 8 \%})$ & $15(15.5 \%)$ & $\mathbf{3 3}(\mathbf{2 0 . 1 \% )}$ \\
\hline Urine & $\mathbf{3 1}(\mathbf{4 6 . 2 \% )}$ & $47(48.4 \%)$ & $\mathbf{7 8 ( 4 7 . 6 \% )}$ \\
\hline Other samples & $6(9 \%)$ & $4(4.1 \%)$ & $10(6.1 \%)$ \\
\hline Total Number & $67(100 \%)$ & $97(100 \%)$ & $164(100 \%)$ \\
\hline
\end{tabular}

Among 164 Candida isolates, 82 were isolated from patients admitted in various wards and an equal number i.e 82 were isolated from ICU patients.

Percentage susceptibility of Candida albicans and major isolates of non-albicans Candida to various anti-fungal agents has been described in Table 4 and Table 5 .

All the isolates of Candida albicans (100\%) were susceptible to Amphotericin B, while least susceptibility was seen for Voriconazole (85\%). In isolates of Candida tropicalis maximum susceptibility was seen to Fluconazole (100\%) while least susceptibility was seen to Voriconazole (93.7\%). Among other non-albicans Candida species susceptibility results were as follows: Among 6 isolates of Candida ciferrii 3 isolates (50\%) were susceptible to all the anti-fungal agents, 2 isolates (33.3\%) were resistant to both Amphotericin B and Voriconazole and 1 isolate (16.7\%) was resistant to Amphotericin B. Among 5 isolates of Candida lusitaniae 4 isolates (80\%) were susceptible to all anti-fungal agents while 1 isolate (20\%) was resistant to Voriconazole and 1 isolate (100\%) of Candida krusei was resistant to Flucytosine. 


\begin{tabular}{|c|c|c|c|}
\hline \multirow{2}{*}{ Antifungal Agent } & \multicolumn{3}{|c|}{ Candida Albicans } \\
\hline & $\begin{array}{l}\text { Sensitive } \\
\text { (\% Susceptibility) }\end{array}$ & Resistant & Total \\
\hline Amphotericin B & $\begin{array}{l}67 \\
(\mathbf{1 0 0 \%})\end{array}$ & $\begin{array}{l}0 \\
(0 \%)\end{array}$ & 67 \\
\hline Caspofungin & $\begin{array}{l}64 \\
(95.5 \%)\end{array}$ & $\begin{array}{l}3 \\
(4.5 \%)\end{array}$ & 67 \\
\hline Flucytosine & $\begin{array}{l}62 \\
(92.5 \%)\end{array}$ & $\begin{array}{l}5 \\
(7.5 \%)\end{array}$ & 67 \\
\hline Fluconazole & $\begin{array}{l}65 \\
(97 \%)\end{array}$ & $\begin{array}{l}2 \\
(3 \%)\end{array}$ & 67 \\
\hline Micafungin & $\begin{array}{l}64 \\
(95.5 \%)\end{array}$ & $\begin{array}{l}3 \\
(4.5 \%)\end{array}$ & 67 \\
\hline Voriconazole & $\begin{array}{l}57 \\
(\mathbf{8 5} \%)\end{array}$ & $\begin{array}{l}10 \\
(15 \%)\end{array}$ & 67 \\
\hline
\end{tabular}

Table 4:-Percentage (\%) susceptibility of Candida albicans

\begin{tabular}{|c|c|c|c|c|}
\hline \multirow[t]{3}{*}{ Antifungal Agent } & \multicolumn{4}{|c|}{ Non-albicans Candida } \\
\hline & \multicolumn{2}{|l|}{$\begin{array}{l}\text { Candida tropicalis } \\
n=48\end{array}$} & \multicolumn{2}{|c|}{$\begin{array}{l}\text { Candida parapsilosis } \\
\mathrm{n}=16\end{array}$} \\
\hline & $\begin{array}{l}\text { Sensitive } \\
\text { (\%Susceptibility) }\end{array}$ & Resistant & $\begin{array}{l}\text { Sensitive } \\
\text { (\%Susceptibility) }\end{array}$ & Resistant \\
\hline Amphotericin B & $\begin{array}{l}47 \\
(98 \%)\end{array}$ & $\begin{array}{l}1 \\
(2 \%)\end{array}$ & $\begin{array}{l}16 \\
(100 \%)\end{array}$ & $\begin{array}{l}0 \\
(0 \%)\end{array}$ \\
\hline Caspofungin & $\begin{array}{l}47 \\
(98 \%)\end{array}$ & $\begin{array}{l}1 \\
(2 \%)\end{array}$ & $\begin{array}{l}16 \\
(100 \%)\end{array}$ & $\begin{array}{l}0 \\
(0 \%)\end{array}$ \\
\hline Flucytosine & $\begin{array}{l}46 \\
(95.8 \%)\end{array}$ & $\begin{array}{l}2 \\
(4.2 \%)\end{array}$ & $\begin{array}{l}15 \\
(93.7 \%)\end{array}$ & $\begin{array}{l}1 \\
(6.3 \%)\end{array}$ \\
\hline Fluconazole & $\begin{array}{l}48 \\
(100 \%)\end{array}$ & $\begin{array}{l}0 \\
(0 \%)\end{array}$ & $\begin{array}{l}16 \\
(100 \%)\end{array}$ & $\begin{array}{l}0 \\
(0 \%)\end{array}$ \\
\hline Micafungin & $\begin{array}{l}47 \\
(98 \%)\end{array}$ & $\begin{array}{l}1 \\
(2 \%)\end{array}$ & $\begin{array}{l}16 \\
(100 \%)\end{array}$ & $\begin{array}{l}0 \\
(0 \%)\end{array}$ \\
\hline Voriconazole & \begin{tabular}{|l|}
45 \\
$(93.7 \%)$ \\
\end{tabular} & $\begin{array}{l}3 \\
(6.3 \%)\end{array}$ & $\begin{array}{l}16 \\
(100 \%)\end{array}$ & $\begin{array}{l}0 \\
(0 \%)\end{array}$ \\
\hline
\end{tabular}

Table 5:-Percentage (\%) susceptibility of non-albicans Candida

Out of 164 Candida isolates 137 isolates (83.5\%) were susceptible to all anti-fungal agents and 27 isolates (16.4\%) were resistant to either 1 or more than 1 anti-fungal agents. Candida isolates showed maximum resistance to Voriconazole (16 isolates) (9.7\%), followed by Flucytosine (9 isolates) (5.5\%), Amphotericin B (4 isolates)

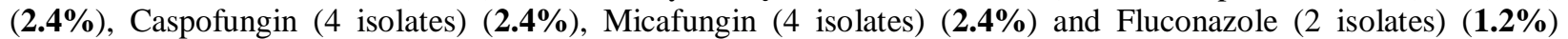
(Diagram 1). Intermediate sensitivity was seen in 3 isolates (1.8\%) to Flucytosine and 6 isolates (3.6\%) showed SDD (susceptible dose dependent) to Fluconazole. Resistance pattern to anti-fungal agents was almost similar among ICU and ward patients except that SDD to Fluconazole was seen more among ward patients (5 isolates). 


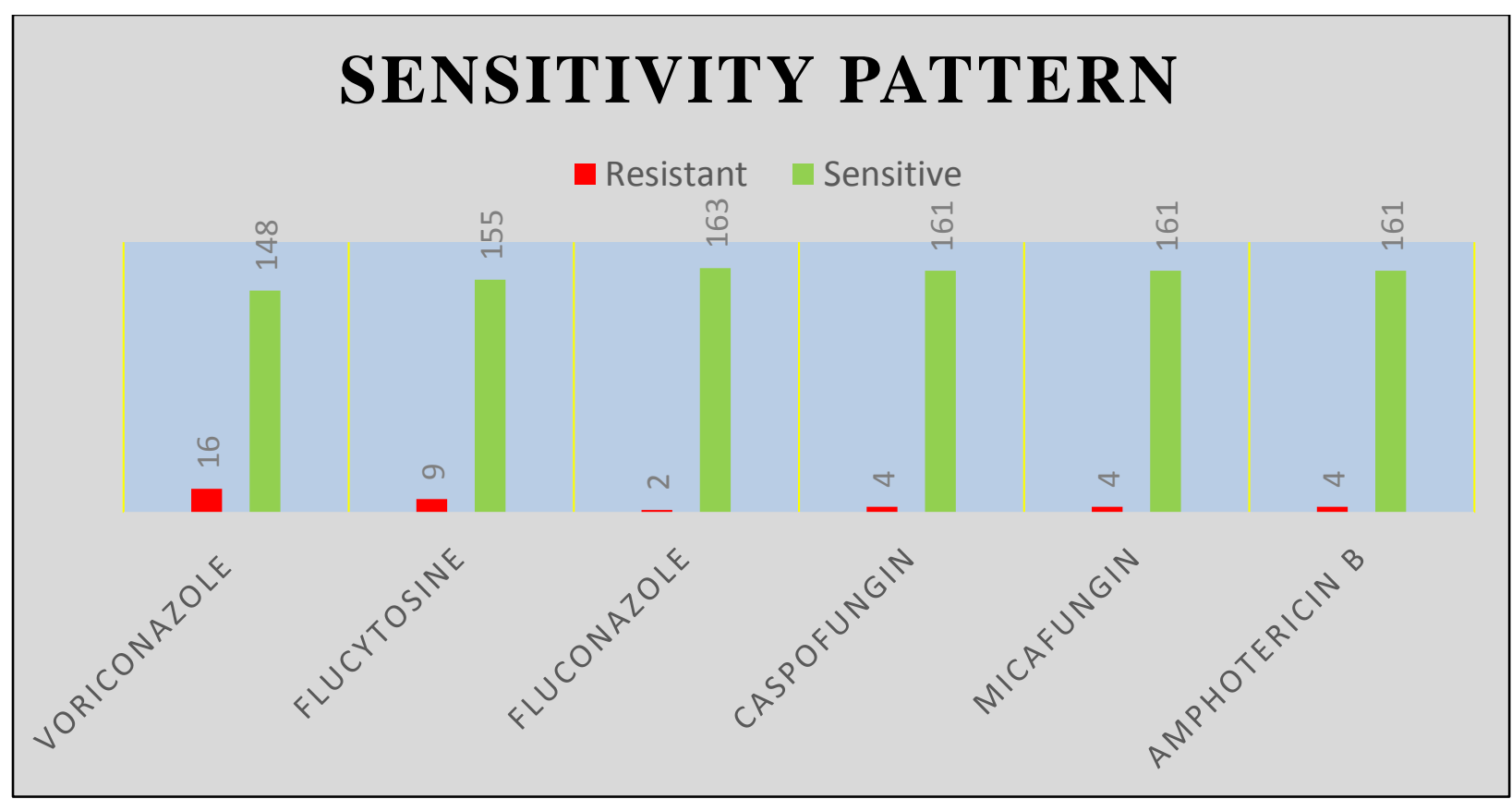

Diagram 1

\section{Discussion:-}

Candidiasis is an emerging problem in healthcare settings. Candida infections are on rise worldwide because of various factors such as uncontrolled use of antibiotics, immunosuppression, increase in transplant surgeries etc. Recent studies have shown that Candida species could cause severe infections with high morbidity and mortality in hospitalized patients. ${ }^{14,}$ 15, 16 Among various Candida species isolated in routine clinical laboratory samples C. albicans, C. glabrata, C. tropicalis, C. parapsilosis, and C. krusei are the most common species. ${ }^{17}$ In our study Candida albicans (40.8\%) was the most common isolate followed by Candida tropicalis $(29.3 \%)$ and Candida parapsilosis (9.7\%) as major isolates which is consistent with the study of Kaur R et al. ${ }^{11}$ Candida albicans has been reported as the most isolated species from patients in various other studies also done in Asian, European, and American countries. ${ }^{15}$ 18-22 Among non-albicans Candida; Candida tropicalis was the most common species isolated in our study which is consistent with the study by Kaur, et al and Lakshmy JA et al. ${ }^{11,23}$

Most Candida isolated were from urine 78 (47.6\%) isolates, out of which $31(46.2 \%)$ isolates were of Candida albicans. About $33(20.1 \%)$ isolates were from sputum. When demographically distributed, about $51 \%$ of the Candida were isolated from adult age group (19-65) and 54\% of the isolates were from male patients.

Our study showed an increase in the antifungal drug resistance, especially for the azole group of drugs, both in C. albicans and non-albicans Candida species which is in agreement with study by Guo-Shi Xiang et al and Kamiar Zomorodian et al. ${ }^{24,25}$ In our study susceptibility to azoles among isolates of Candida albicans was $85 \%$ and $97 \%$ to Voriconazole and Fluconazole respectively. Candida tropicalis showed $93.7 \%$ susceptibility to Voriconazole.

Echinocandin (Caspofungin and Micafungin) resistance among Candida species is uncommon ${ }^{\mathbf{2 6}}$, in our study it was found to be $(2.4 \%)$ which was consistent with study by Mariana Castanheira et al. Resistance to amphotericin B among isolates of Candida are limited ${ }^{27}$ which was consistent with our study as only (2.4\%) of the isolates were resistant to Amphotericin B; but 3 out of 4 Candida isolates resistant to Amphotericin B were Candida ciferrii.

Primary resistance to Flucytosine or 5-fluorocytosine (5-FC) is a common finding among yeasts, and this agent is subject to developing secondary resistance in patients taking Flucytosine monotherapy. Thus Flucytosine has been specifically used only in combination specifically with Amphotericin B. ${ }^{28}$ In our study 9 isolates were resistant to Flucytosine. 


\section{Conclusion:-}

Candida infections in hospitalized patients is a significant problem worldwide. Resistance among Candida species is increasing and various species already have inherent resistance to some commonly used antifungals. The rising burden of Candida infections and ever increasing anti-fungal resistance among Candida species necessitates accurate and rapid identification of Candida isolates for better patient outcome as any delay can result in increased mortality and morbidity in patients. Non-albicans Candida species are on rise, especially C. tropicalis which was the most frequent non-albicans Candida isolated in our tertiary care center. Resistance among Candida species to various antifungal agents especially to azole group of drugs is on rise as is evident from our study also which can increase further in future if steps are not taken to control it. Based on the present results, it is evident that routine identification of Candida isolates to the species level, and the detection of resistant strains by antifungal susceptibility test is essential. Furthermore, there is a continued need for surveillance of Candida infections to monitor changes in the epidemiological features and antifungal susceptibility and also to develop and evaluate prevention strategies.

\section{Acknowledgement:-}

We are thankful to all the teaching and non-teaching staff of our department for their help and suggestions. We are also thankful to the ethical committee for permitting us to conduct this study.

\section{Conflict of interest:}

None.

\section{Financial assistance:}

None.

\section{Refrences:-}

1. Bailey and Scott's Diagnostic Microbiology ( $14^{\text {th }}$ edition; page 827$)$.

2. Arendrup, M. C., Fuursted, K., Gahrn-Hansen, B., Jensen, I. M. Knudsen, J. D., Lundgren, B., Schonheyder, H. C. \& Tvede, M. (2005). Seminational surveillance of fungemia in Denmark: notably high rates of fungemia and numbers of isolates with reduced azole susceptibility. J Clin Microbiol 43, 4434-4440.

3. Espinel-Ingroff, A., Canton, E., Peman, J., Rinaldi, M. G. \& Fothergill A.W. (2009). Comparison of 24-hour and 48-hour voriconazole MICs as determined by the Clinical and Laboratory Standards Institute broth microdilution method (M27-A3 document) in three laboratories: results obtained with 2,162 clinical isolates of Candida spp. And other yeasts. J Clin Microbiol 47, 2766-2771.

4. Koneman's Color atlas and textbook of diagnostic microbiology $\left(6^{\text {th }}\right.$ Edition; page 1221).

5. Pfaller MA, Diekema DJ, Gibbs DL, et al. Results from the ARTEMIS DISK Global Antifungal Surveillance Study, 1997 to 2007: a 10.5- year analysis of susceptibilities of Candida species to fluconazole and voriconazole as determined by CLSI standardized disk diffusion. J Clin Microbiol 2010; 48: 1366-77.

6. Ostrosky-Zeichner L, Rex JH, Pappas PG, et al. Antifungal susceptibility survey of 2,000 bloodstream Candida isolates in the United States. Antimicrob Agents Chemother 2003; 47: 3149-54.

7. Dannaoui E, Lortholary O, Raoux D, et al. Comparative in vitro activities of caspofungin and micafungin, determined using the method of the European Committee on Antimicrobial Susceptibility Testing, against yeast isolates obtained in France in 2005-2006. Antimicrob Agents Chemother 2008; 52: 778-81.

8. Sachin C. Deorukhkar, Santosh Saini, and Stephen Mathew, "Non-albicans Candida Infection: An Emerging Threat," Interdisciplinary Perspectives on Infectious Diseases, vol. 2014, Article ID 615958, 7 pages, 2014. https://doi.org/10.1155/2014/615958.

9. Wadlin JK, Hanko G, Stewart R, Pape J, Nachamkin I. Comparison of three commercial systems for identification of yeasts commonly isolated in the clinical microbiology laboratory. J Clin Microbiol 1999; 37:1967-70.

10. Crist AE Jr., Johnson LM, Burke PJ. Evaluation of the microbial identification system for identification of clinically isolated yeasts. J Clin Microbiol 1996; 34:2408-10.

11. Kaur R, Dhakad MS, Goyal R, Haque A, Mukhopadhyay G. Identification and Antifungal susceptibility testing of Candida species: A Comparison of Vitek-2 system with conventional and molecular methods. J Global Infect Dis 2016; 8:139-46. 
12. Morrell M, Fraser VJ, Kollef MH. Delaying the empiric treatment of Candida bloodstream infection until positive blood culture results are obtained: A potential risk factor for hospital mortality. Antimicrob Agents Chemother 2005; 49:3640-5.

13. Essentials of Medical Microbiology ( $1^{\text {st }}$ edition; page no. 568).

14. Badiee P, Alborzi A, Vojdani R, Shakiba E, Rasouli M, Ravanfar P, et al. Early diagnosis of systemic candidiasis in bone marrow transplant recipients. Exp Clin Transplant. 2010; 8(2):98-103. [PubMed: 20565365].

15. Colombo AL, Guimaraes T, Sukienik T, Pasqualotto AC, Andreotti R, Queiroz-Telles F, et al. Prognostic factors and historical trends in the epidemiology of candidemia in critically ill patients: an analysis of five multicenter studies sequentially conducted over a 9-year period. Intensive Care Med. 2014; 40(10):1489-98. doi: 10.1007/s00134-014- 3400-y. [PubMed: 25082359].

16. Lortholary O, Renaudat C, Sitbon K, Madec Y, Denoeud-Ndam L, Wolff M, et al. Worrisome trends in incidence and mortality of candidemia in intensive care units (Paris area, 2002-2010). Intensive Care Med. 2014; 40(9):1303-12. doi: 10.1007/s00134-014-3408-3. [PubMed: 25097069].

17. Graf B, Adam T, Zill E, Göbel UB. Evaluation of the VITEK 2 system for rapid identification of yeasts and yeast-like organisms. J Clin Microbiol 2000; 38:1782-5.

18. Pfaller MA, Diekema DJ. Epidemiology of invasive mycoses in North America. Crit Rev Microbiol. 2010; 36(1):1-53. doi: 10.3109/10408410903241444. [PubMed 20088682].

19. Shokohi T, Bandalizadeh Z, Hedayati MT, Mayahi S. In vitro antifungal nsusceptibility of Candida species isolated from oropharyngeal lesions of patients with cancer to some antifungal agents. Jundishapur J Microbiol. 2011; 4(Supplement 1):S19-S26.

20. Badiee P, Amirghofran AA, Nour MG, Shafa M, Nemati MH. Incidence and outcome of documented fungal endocarditis. Int Cardiovasc Res J. 2014 Dec; 8(4):152. doi: 25614858.

21. Ghasemi Z, Hashemi SJ, Rezaei S, Kordbache P, Khosravi M, Mortazavi H, et al. Molecular Analysis of Candida species with Emphasis on Predisposing Factors in Cutaneous Candidiasis Patients. Jundishapur J Microbiol. 2016; 10(2):e41030. doi: 10.5812/jjm.41030.

22. Wang H, Xiao M, Chen SC, Kong F, Sun ZY, Liao K, et al. In vitro susceptibilities of yeast species to fluconazole and voriconazole as determined by the 2010 National China Hospital Invasive Fungal Surveillance Net (CHIF-NET) study. J Clin Microbiol. 2012;50(12):3952-9. doi: 10.1128/JCM.01130-12. [PubMed: 23035204].

23. J. Abirami Lakshmy, Radhika Katragadda, J. Balaji; Speciation and antifungal susceptibility of esophageal candidiasis in cancer patients in a tertiary care hospital in South India; J Med Allied Sci 2016; 6(1):29-34 DOI: 10.5455/jmas.214436.

24. Guo-Shi Xiang, Ling-Bing Zeng, Jie-Yu Zhang, Ying Ying, Xi-Ren Deng, Xue-Fei Hu, Yan Yan,Ke-Hua Yu,1 Wei-Wen Zou, and Xiao-Tian Huang; In Vitro Antidrug Susceptibility Testing of Candida Species Isolated from Aseptic Body Fluids; Jundishapur J Microbiol. 2018 August; 11(8):e55547. Published online 2018 July 25. doi: $10.5812 /$ jjm.55547.

25. Kamiar Zomorodian, Azadeh Bandegani, Hossein Mirhendi, Keyvan Pakshir, Navvab Alinejhad, and Ali Poostforoush Fard; In Vitro Susceptibility and Trailing Growth Effect of Clinical Isolates of Candida Species to Azole Drugs; Jundishapur J Microbiol. 2016; 9(2): e28666. doi: 10.5812/jjm.28666

26. Echinocandin Resistance in Candida; David S. Perlin; Clin Infect Dis. 2015 Dec 1; 61(Suppl 6): S612S617. Published online 2015 Nov 5. doi: 10.1093/cid/civ791; PMCID:PMC4643482

27. Giri S, Kindo AJ. A review of Candida species causing blood stream infection. Indian J Med Microbiol 2012; 30:270-8.

28. M. Cuenca-Estrella, T. M. Díaz-Guerra, E. Mellado, J. L. Rodríguez-Tudela. Flucytosine Primary Resistance in Candida Species and Cryptococcus neoformans; Eur J Clin Microbiol Infect Dis (2001) 20:276-279. 